\title{
Prevalence of trypanosomosis in small ruminants of Guto Gidda district, East Wellega zone, western Ethiopia
}

\author{
Abebayehu Tadesse* and Gurarra Megerssa \\ * Department of Parasitology and Pathology, Faculty of Veterinary Medicine, Hawassa \\ * Corresponding author: abutadesse2@yahoo.com
}

\section{Abstract}

\begin{abstract}
A cross sectional study was conducted in Anger river valley and its tributaries from November to April 2008 to determine the prevalence of trypanosomosis in small ruminants. Blood samples were collected from 379 randomly selected local sheep (145) and goats (234) of different sex, age and body condition in five peasant associations. The collected samples were examined by haematological and parasitological techniques. Of the total small ruminants examined during the study period, 8 animals $(2.11 \%)$ were infected with trypanosomes, of which 4 (2.76\%) were sheep and $4(1.70 \%)$ goats. Most of the infections were due to T. congolense $(1.37 \%, 0.42 \%)$ and T. vivax $(1.37 \%, 1.28 \%)$ in sheep and goats respectively. There was no statistical significance difference $(P>0.05)$ between species, sex, age and body conditions. The difference in mean PCV of parasitaemic (24.13\%) and aparasitaemic (25.1\%) animals was not significant $(P>0.05)$. Tsetse flies of riverine species or palpalis group (Glossina tachinoides) and mechanical vectors of the disease such as tabanus, stomoxys and haematopota were captured during entomological study. The overall apparent densities of tsetse and biting flies were 10.5 and 14.31 flies/trap/day respectively. The difference in overall fly count among peasant associations was significant $(P<0.05)$. The study revealed that trypanosomosis in small ruminants are an important disease that serves as potential reservoir for the transmission to other livestock. Although the present study revealed low prevalence $(2.11 \%)$ trypanosomosis in small ruminant of the study area its impact on production and potential transmission to other livestock should not be neglected.
\end{abstract}

Keywords: Prevalence, Trypanosomosis, Sheep, Goats, Guto Gidda, Ethiopia.

\section{Introduction}

In tsetse infested areas animal trypanosomosis is the most rampant livestock disease caused by a variety of species and sub species of the genus Trypanosoma (Swalow, 2000). In Ethiopia, Animal trypanosomosis affects all domestic 
animals (Cattle, sheep, goats, equines and camels) and costs livestock producers and consumers substantial amount from direct and indirect effects (Getachew Abebe, 2005). The most important trypanosomes in terms of economic loss in domestic livestock are the tsetse transmitted species such as T. congolense, T. vivax, and T. brucei in cattle, sheep and goats (Getachew Abebe and Yilma Jobre, 1996; Getachew Abebe, 2005).

In Ethiopia, the tsetse flies are confined to the southern, southwestern and and north western regions where there are five species of tsetse fly (Glossina): namely G. morsitans submorsitans, G. pallidipes, G .f. fuscipes, G. tachnoids and $G$. longipennis. Among these species the first four are widespread and most important while G. longipennis is of minor economic importance (Langridge, 1976; Getachew Abebe, 2005).

Although bovine trypanosomosis considered an important livestock disease in Ethiopia, little is known of the prevalence of trypanosome infections in sheep and goats in the area. This study was carried out to determine the prevalence of trypanosomosis in small ruminants in Guto Gidda district and to asses the density of different fly species that are responsible for transmitting the disease.

\section{Materials and methods}

Study area

The study was conducted from November to April 2008 in Guto Gidda district of Anger river basin and its tributaries. Guto Gidda district is found in East Wollega zone and located some $335 \mathrm{kms}$ from Addis Ababa in the western direction of the country, which lies within the altitude range of 1350 to $2450 \mathrm{~m}$ above sea level.

\section{The Agro climatic Condition}

The valley possess a typical climate with an annual rain fall ranging from 1320 to $1630 \mathrm{~mm}$, minimum and maximum temperature ranges from $21^{\circ} \mathrm{C}$ to $34^{\circ} \mathrm{C}$. The valley had a richer vegetation and wild fauna from which only little have been left. In this district human population mainly resides in high land areas. On the other hand, the low land area where the former mechanized state farms are located is scarcely populated. However; most of the lowlands are currently used by investors as part of government investment in agricultural sector in area (EWZADO, 2007). 
The dominant livestock populations are cattle, sheep and goats where all of them raised under traditional management system. The total livestock population of this woreda is estimated to be 12593 cattle, 7776 shoats and 2222 equines. Mixed livestock crop farming is the dominant form of production system. The purpose of cattle production is for draught power and milk production while sheep and goats are raised both for house hold consumption and income generation (EWZADO, 2007).

Study animals

This study was carried on 145 local sheep and 234 goats selected by random sampling methods in the five peasant associations. Information was obtained on the sex, species, age of the small ruminants, altitude of the sites and packed cell volume (PCV) from collected blood samples. The age of the animals was estimated on the basis of the dentition formula descried by Gatenby (1991) and Mike (1996) in which animals under 1 year were considered as young animals.

\section{Study Design}

The cross sectional type of study was used with the assumption that it could help to get an understanding of the current state of problem by describing the prevalence of trypanosomosis in small ruminant in upper valley of Anger and to assess the fly density.

\section{Parasitological study}

Blood samples were collected from ear vein of animal using two microhaematocrit capillary tubes and the PCV was determined. The trypanosome species were identified using Giemsa stained thin blood films (Murray et al 1977). This technique is the most sensitive of the parasitological tests for the detection of T. vivax and T. congolense (Murray et al., 1983; Murray et al 1977). Anemia was estimated by the Packed Cell Volume (PCV) where animals were considered anemic if the PCV $\leq 24$ (Van den Bossche et al., 2000).

\section{Entomological Study}

The study was also carried out to assess the apparent density, species of tsetse and other biting flies in the study area. During the study 34 monopyramidal traps available were deployed in selected sites which seem suitable habitat for tsetse flies. Every trap was odour baited either with acetone, octenol or cow urine, which was odour attractants for tsetse flies. The underneath of each 
trap pole was smeared with grease in order to prevent the ants climbing up the pole towards the collecting cage that could damage the tsetse flies. The trap deployment time was 48 hours. After the flies captured in the collecting cage they were then sorted by sex, species, and sites and recorded. The species of tsetse was identified based on the characteristic morphology. Other biting flies were also separated according to their morphological characteristics such as size, colour, proboscis and wing venation structures at the genus level (Langridge, 1976; Fischer and Say, 1989).

Sample size and sampling method

The sample size was determined with $50 \%$ expected prevalence to increase the precision of the data using the formula described by Thrustfield, (1995).

$n=\underline{1.96} \underline{\underline{2}} \underline{(P \exp (1-P \exp ))}$

$d^{2}$

Where, $\mathrm{n}$ - The sample size

d-The desired absolute precision

p-The expected prevalence

Accordingly, a total of 379 small ruminants were randomly sampled from five peasant associations to determine the prevalence of trypanosomosis in small ruminant.

Data analysis

Data on individual animals and parasitological examination results was inserted in to Ms- excel spread sheet program to create a data base and transferred to the STATA soft ware version 9 (2001) program of the computer before analysis. The prevalence of trypanosomes infection was calculated as the number of parasitological positive animals as examined by the buffy coat method (Murry et al., 1983) divided by the total number of animals investigated at that particular time and multiplying by 100 .

Logistic regression model was fitted to the data to establish the interaction of different risk factors such as site, sex, age and body condition. Two sample t-tests were utilized to compare the mean PCV values of the parasitaemic and aparasitaemic animals. Differences between parameters were tested for sig- 
nificance at probability levels of 0.05 or less. Poisson regression was also used to determine the count of the fly per PAs, species and sexes.

\section{Results}

Parasitological findings:

The over all prevalence of trypanosomosis in small ruminant of the study area was $2.11 \%$. The prevalence of trypanosomosis in sheep and goats was $2.76 \%$ and $1.70 \%$ respectively. The prevalence of T. vivax in sheep and goat was $1.37 \%$ and $1.28 \%$ respectively. Similarly the prevalence of $\mathrm{T}$. congolense was $1.37 \%$ in sheep and $0.42 \%$ in goats (Table 1 ). The difference in the trypanosome prevalence between the two species was no significance $(\mathrm{P}>0.05)$ (Table 2$)$.

Table 1 Prevalence of trypanosomosis in small ruminants

\begin{tabular}{lllcc}
\hline & No of animals & $\begin{array}{l}\text { No. of positive } \\
\text { animals }\end{array}$ & \multicolumn{2}{c}{ Prevalence (\%) } \\
\cline { 3 - 5 } & 145 & 4 & $2(1.37)$ & T. congolense \\
\hline Sheep & 234 & 4 & $3(1.28)$ & $2(1.37)$ \\
Goats & 145 . vivax & $1(0.42)$ \\
\hline
\end{tabular}

From the total 379 small ruminants examined, 3 (2.52\%) male and $5(1.89 \%)$ female animals were found positive for trypanosomosis. Like wise, 1 (0.59\%) young and 7 (3.31\%) adults were found infected by trypanosomes. The prevalence in good and poor body conditioned animals was $1.82 \%$ and $2.32 \%$ respectively. The difference in trypanosome prevalence among all groups tested was not significant $(P>0.05)$.

Hematological findings

The overall mean PCV recorded for parasitaemic and aparasitaemic animals were $24.1 \%$ and $25.1 \%$ respectively and the difference was not significant $(\mathrm{P}>0.05)$ (Table 2) 
Abebayehu Tadesse, et al.

Table 2 Mean PCV of parasitaemic and aparasitaemic animals

\begin{tabular}{lccc}
\hline Animals & No. of examined & Mean PCV & $\mathrm{Cl}(95 \%)$ \\
\hline Non-infected & 371 & 25.05 & $(24.64,25.46)$ \\
Infected & 8 & 24.125 & $(21.43,26.82)$ \\
\hline
\end{tabular}

The difference in mean PCV value of parasitaemic (23.25\%) and aparasitaemic $(25.60 \%)$ sheep was not significant (P0>05). Similar finding was observed in mean PCV of parasitaemic (22\%) and aparasitaemic (24.85\%) goats (Table 3).

Table 3 Mean PCV of parasitaemic and aparasitaemic animals in sheep and goats

\begin{tabular}{lllll}
\hline Species & Status & Mean PCV $(\%)$ & $95 \% \mathrm{Cl}$ & P-Value \\
\hline Sheep & Parasitaemic & 23.25 & {$[16.70,29.79]$} & 0.86 \\
& Aparasitaemic & 25.60 & {$[24.90,26.30]$} & 0.27 \\
& Over all & 25.53 & {$[24.84,26.23]$} & 0.13 \\
\multirow{3}{*}{ Goat } & Parasitaemic & 22.00 & {$[18.56,25.43]$} & 0.94 \\
& Aparasitaemic & 24.85 & {$[24.25,18.56]$} & 0.11 \\
& Over all & 24.77 & {$[24.18,25.35]$} & 0.06 \\
\hline
\end{tabular}

Entomological finding

From 34 traps deployed at the four PAs, a total of 1687 flies were caught. Out of which $714(42.32 \%)$ were Glossina tachinoides and 973 (57.68\%) were other biting flies such as tabanus, stomoxys and haematopota. The number of fly counted differs significantly $(P<0.05)$ among peasant associations and between tsetse and other biting flies (Table5). During the study $46 \%$ female and $54 \%$ male G. tachinoides were caught and the difference was significant $(P<0.05)$ (Figure1). 
Table 2: The count of Glossina and other biting flies caught by monopyramidal trap in different PAs of the study area

\begin{tabular}{|c|c|c|c|c|c|c|c|c|c|c|c|}
\hline \multirow[t]{2}{*}{ No } & \multirow[t]{2}{*}{ PAs } & \multirow[t]{2}{*}{ Altitude } & \multirow{2}{*}{$\begin{array}{l}\text { Number } \\
\text { of trap }\end{array}$} & \multicolumn{4}{|c|}{ Glossina tachinoides } & \multirow{2}{*}{$\begin{array}{l}\text { Sto- } \\
\text { moxys }\end{array}$} & \multirow{2}{*}{$\begin{array}{l}\text { Ta- } \\
\text { banus }\end{array}$} & \multirow{2}{*}{$\begin{array}{l}\text { Hae- } \\
\text { matopota }\end{array}$} & \multirow{2}{*}{$\begin{array}{l}\text { Total of } \\
\text { biting } \\
\text { flies }\end{array}$} \\
\hline & & & & $M$ & $\mathrm{~F}$ & $\mathrm{~T}$ & FTD * & & & & \\
\hline 1 & $\begin{array}{l}\text { Lugo } \\
\text { first } \\
\text { camp }\end{array}$ & $1337-1388 m$ & 11 & 4 & 3 & 7 & 0.32 & 187 & 15 & 34 & 236 \\
\hline 2 & $\begin{array}{l}\text { Lugo } \\
\text { fifth } \\
\text { camp }\end{array}$ & $1332-1567 m$ & 13 & 1 & 3 & 4 & 0.15 & 344 & 18 & 74 & 436 \\
\hline 3 & Horro & $1284-1328 m$ & 5 & 177 & 140 & 317 & 31.7 & 42 & 9 & 80 & 131 \\
\hline 4 & Meti & $1269-1286 m$ & 5 & 214 & 172 & 386 & 38.6 & 36 & 14 & 120 & 170 \\
\hline $\mathrm{T}$ & & & 34 & 396 & 318 & 714 & 10.5 & 609 & 56 & 308 & 973 \\
\hline
\end{tabular}

FTD* fly catch per trap per day, $M=$ male, $F=F e m a l e, T=$ Total catch

\section{Discussion}

The overall prevalence of trypanosomosis in small ruminants of the study area was $2.11 \%$. This finding was lower than the reports from other parts of Ethiopia by Hundema Dinka and Getachew Abebe (2005) who reported a prevalence of $5.1 \%$ in Didessa and Ghibe valley. Similar low prevalence of $5.45 \%$ and 5.37 $\%$ was observed by Shikure (1995) and Bezabeh (1987) in different parts of the country. The low prevalence of trypanosomosis in small ruminants by the recent study may be attributed to application of control measures such as target impregnated insecticides, trapping and regular treatment of sick animals.

Higher prevalence of trypanosomosis was reported in sheep $(2.76 \%)$ than in goats $(1.70 \%)$. This report was higher than the finding of Hailemariam Lemecha et al. (2002) who reported $2.0 \%$ and $0.4 \%$ in sheep and goats respectively. Like wise it was higher than the findings of Kalu (1996) who observed a prevalence of $1.2 \%$ in sheep and $0.7 \%$ in goats. However it is lower than the findings of Dinka and Ababe (2005) who reported $7.6 \%$ in sheep and 3.6\% in goats. Several authors have shown that the prevalence was low in goats than in sheep because of nature of the goat and sheep. This was usually related to tsetse feeding where the anti feeding behavour of goats and the docile nature and wool cover of the sheep (Snow et al., 1996; Stephen, 1986; Murray, 1988 and Bealby et al., 1996).

Trypanosoma vivax and T. congolense were the only two species of trypanosomes identified in the study area. Similar findings were reported by (Mulli- 
gan, 1970, Samdi, 2008) who concluded T. congolense and T. vivax are trypanosomes of major threats to sheep and goats.

The statistical analysis result revealed that there was no significant difference $(\mathrm{P}>0.05)$ in prevalence between female and male. Dinka and Abebe (2005) reported similar finding. Small ruminants of both sexes of the study area were grazing together and they might have acquired the infection since they have equal chance of contracting the disease. Although the difference $(P>0.05)$ in the prevalence between age groups was not significant, the current finding indicated higher prevalence in adults than young animals. Since adult animals of the study area, were generally kept in the field for long periods of time which might predispose them to fly bite than young animals which were usually kept indoor. Several other authors in the same way described that the adult animals were frequently affected than the young animals (Dinka and Abebe 2005; Stephen, 1986; Murray, 1988 and Bealby et al., 1996). The higher prevalence of trypanosome infection was observed in animal of poor body condition than good body condition. This might be attributed due to poor management and husbandry practices.

The PCV value was calculated by taking in account (22-45\%) as normal PCV for sheep and (22-38\%) for goats (Radostitis et al., 2000). The mean PCV value of parasitaemic sheep (23.25\%) and goats (22.00\%) was not significantly different $(\mathrm{P}>0.05)$ from those of the non infected sheep $(25.6 \%)$ and goats $(24.85 \%)$. This indicated that PCV value alone could not be used for diagnostic criterion for trypanosomosis but there are also other factors causing anemia such as worm infestation and nutritional deficiency (Radostitis et al., 2000).

The overall apparent density of tsetse was 10.5 flies/trap/day (FTD). This finding was lower than 14.5 FTD recorded previously in the area (NTTICC, 2006). The lower value of fly density by the current study might be due to the control measure under taken by National Tsetse and Trypanosomosis Investigation and Control Center (NTTICC, 2006) in the area. The use of the fly habitats for cultivation by settlers might contribute for the reported lower density than the previous reports of other authors. There was significant difference $(P<0.05)$ in overall fly count in between peasant associations. Other studies have shown that as altitude decreases tsetse apparent density and trypanosomosis increase (Muturi, 1999). 


\section{Conclusions}

The overall prevalence of trypanosomosis in small ruminants in the area was $2.11 \%$. This implies the endemicity of the disease with potential reservoir host to other livestock particularly a serious treat to cattle production. This finding also indicated that the prevalence in sheep was higher compared to goats and also aged animals were more likely to be infected with trypanosomois, regardless of the species they belong. The most commonly encountered trypanosome species in the area were T. vivax and T. congolense. The only tsetse fly identified in the area was Glossina tachinoides and also other biting flies possibly transmitting T. vivax (tabanus, stomoxys and haematopota) were identified.

Although the prevalence of trypanosomosis was low in the study area its potential impact on small ruminant production and its role as reservoir of the infection should not be neglected. Therefore, particular attention towards T. vivax and T. congolense infections are essential to control the impact of the disease on small ruminants that are the potential reservoir of the infections. Development of control options that could minimize biting and tsetse flies are another task.

\section{References}

Bealby, K. A., Connor, R. J., Rowlands, G. J. 1996. Trypanosomosis of goats in Zambia. ILRI, Nairobi, Kenya.

Bezabeh, G. 1987. Prevalence of trypanosomosis in small ruminants in Arbaminch. DVM thesis, Faculty of Veterinary Medicine, Addis Ababa University.

EWZADO (East Wollega Zone Agriculural Development Office), 2007. Annual report.

Fischer, Say (1989): Methods for studying Trypanosomosis and their Vectors. Manual of Tropical Veterinary Parasitology. CIA, CAB international.

Gatenby, R.M. 1991. Sheep in the tropical Agriculturalist, Macmillan, TCTA, Pp5-10

Abebe, G. 2005. Trypanosomosis in Ethiopia. Ethiop. J. Biol. Sci., 4 (1): 75-121.

Abebe, G. and Jobre, Y. 1996. Trypanosomosis: a threat to cattle production in Ethiopia. Rev. Vet. Med. 147. 897-902.

Holmes, P.H., 1997. New approaches to the integrated control of trypanosomosis Vet. Parasitol. 71:121-135.

Ethiop. Vet. J., 2010, 14 (2), 67-77 
Lemecha, H., Hussein, I., and Lidetu, D. 2002. Prevalence and Distribution of major Vector born parasite Infections in Domestic Ruminants and Equine in Ethiopia. National animal health research center, Sebeta.

Dinka, H. and Abebe, G. (2005): Small ruminants trypanosomosis in southwest of Ethiopia. Small. Rumin .Res., 57: 239-243.

Kalu, A. U., Uzoigwe, N. R. 1996. Tsetse fly and trap on the Jos plateau.observation on out breaks in B/Ladi L.G., Act.Trop. 14:114-126.

Langridge, W. P. 1976. A tsetse and trypanosomosis survey of Ethiopia. Ministry of over seas Development of British and Ministry of Agriculture of Ethiopia, Addis Ababa Ethiopia.

Mike S, 1996. Goats: In the Tropical Agriculturalists, Macmillan, TCTA, Pp.79-83.

Mulligan H. W., 1970. The African Trypanosomosis pp. 950. London: George Allen and Unwin Ltd.

Muturi, K. S.,1999. Epidemiology of bovine trypanosomosis in selected sites of southern Rift Valley of Ethiopia.MSc Thesis,AddisAbaba and Free University of Berlin.

Murray, M., Dexter, T. M., 1988. Anaemia in bovine African trypanosomiasis. Acta Trop. 45: 389-432.

Murray, M., Trial, T. M., Turner, D.A. and Wissoq, V.,1983. Livestock productivity and trypanotolerance. Network Training Manual. International livestock center for Africa. P.O.Box 5689. Addis Ababa, Ethiopia.

Murray, M., Murray, P. K., Mcintyre, W. I. M.,1977. An improved technique for the diagnosis of African typanosomiasis. Trans.R. Soc. Trop. Med. Hyg.71:325-326.

NTTICC (National Tsetse and Trypanosomosis Investigation and Control Center) 1996. Annual Report, Bedelle, Ethiopia

NTTICC (National Tsetse and Trypanosomosis Investigation and Control Center), 2006. Annual Report, Bedelle, Ethiopia.

Paris, J., Murray, M. and Mc Odimba, F., 1982. A comparative evaluation of the parasitological techniques currently available for the diagnosis of African trypanosomosis in cattle. Acta Trop. 39:307. 
Radostitis, D.M., Gray, C. C., Blood, D. C., Hinchelift, K. W., 2000. Veterinary Medicine, A textbook of the Diseases of cattle, sheep, pigs, goat and horses, $9^{\text {th }}$ ed. W B. Saunders Company Ltd. London: pp.1329-1337

Samdi, S., 2008. Seasenal variation in trypanosomosis rates in a small ruminants at the kaduna abattoir, Nigeria.

Shukre, M., 1995. Prevalence of trypanosomosis in small ruminants in Wolayta. DVM thesis, Faculty of Veterinary Medicine, Addis Ababa University.

Snow, W. F., Watcher, T. J., Rawlings, P.,1996. Observation on the prevalence of trypanosomosis in small ruminants, equines and cattle in relation to tsetse challenge, in the Gambia. Vet.Parasitol., 66(1-2):1-11.

Swallow, B.M., 2000. Impacts of trypanosomosis in African agriculture. In PAAT technical and scientific series No. 2, FAO, Rome.

Stephen L. E.,1986. Trypanosomosis: A veterinary perspective perganun press, UK.

Thrustfield, M., 1995. Sampling in: Veterinary epidemiology, $2^{\text {nd }}$ ed. London, Black well science Ltd. pp. 179-284.

Ethiop. Vet. J., 2010, 14 (2), 67-77 